\title{
CLINICAL EVALUATION OF DEXTROSE PROLOTHERAPY FOR MANAGEMENT OF TEMPOROMANDIBULAR JOINT DISORDER
}

\author{
Adel M. ELwerfelli ${ }^{1} B D S$, Abd Elaziz F. Kalil ${ }^{2} P h D$, Nevein S. Abdullah ${ }^{2} P h D$
}

\begin{abstract}
INTRODUCTION: Temporomandibular disorders (TMDs) are clinically significant conditions which can be a source of acute or chronic orofacial pain and dysfunction including limitation of mandibular movement. Simple lysis and lavage in the upper joint space which washes out inflammatory mediators were found to be highly effective in reestablishing normal maximum interincisal opening (MIO), jaw function and relieving the symptoms despite the disc position not have been corrected.

OBJECTIVES: To evaluate the efficiency of arthrocentesis, used normal saline, followed by injection of dextrose $50 \%$, in a single injection protocol, for management of patients with TMDs.

MATERIALS AND METHODS: This study was conducted on fourteen TMD patients have been diagnosed on the bases of the clinical data and MRI findings. The selected patients were divided equally into two groups, each group comprising of seven patients. The group-A: has been treated by arthrocentesis followed by $2 \mathrm{ml}$ of dextrose $50 \%$ injected into the superior compartment of TMJ. The group-B: has been treated with arthrocentesis alone. All patients have been evaluated at the end of the 24 hours, 1st, 2nd, 3rd, 4th, 5th and 6th weeks postoperatively. RESULTS: unassisted mouth opening showed an increase at all time intervals. There was a significant improvement in pain, the range of motion, joint effusion and joint sounds.

CONCLUSIONS: Arthrocentesis followed by $50 \%$ dextrose injection is superior to arthrocentesis alone in reducing impairment in patients with TMDs on its clinical outcome.
\end{abstract}

KEYWORDS: Range of motion, Arthrocentesis, Intra-articular injection, Maximum interincisal opening, Dextrose Prolotherapy.

1- BDS, Faculty of Dentistry, Tripoli University, Libya.

2- Professor of Oral \& Maxillofacial Surgery, Faculty of Dentistry, Alexandria University, Egypt.

Corresponding author:

E-mail: adeltabb2008@gmail.com

\section{INTRODUCTION}

TMD is a collective term embracing a broad spectrum of clinical joint and muscle problems in the orofacial area, these disorders characterized by pain, limited and irregular jaw function, and joint sounds. The pathogenesis of internal derangement of the Temporomandibular Joint (TMJ) has shifted focus from a disc displacement theory with more emphasis on the biochemical causes (1,2,3-5).

Some suggest that TMJ internal derangement was progressed from a stage of retrodiscal elongation as a result of lateral pterygoid muscle hyperactivity. The internal derangement in early stage had an elongation of retrodiscal tissues with normal MIO, then gradually progressed with varying degrees of restriction in mouth opening to disc displacement with reduction and later stage of closed-lock disc displacement without reduction (6). The latter stage is attributed to a clinical state of non-reducible anteriorly displaced disc acting as an obstacle to the gliding condyle $(7,8)$.

The simple lysis and lavage in the upper joint space is effective in reestablishing normal MIO, jaw function and relieving the symptoms despite the disc position not have been corrected (9-11).

In the literature, two broad approaches of explanation for TMD pathogenesis; The Mechanical-based approach that focusing on positional changes occurring within the joint to explain most of the clinical manifestations related to TMJ disorder. The pathological-based approach that focusing on structural changes occurring within the joint to explain the clinical manifestations related to TMJ disorder. $(1,2,4,12)$.
The pathological-based approaches used the signs of inflammation in the TMJs patients with longstanding pain and tenderness to explain an underlying mechanism of TMJ-dysfunction and the pathogenesis of TMD $(13,14)$.

Several authors $(1,2,4,12,13,14)$, reported that the symptomatic treatment mainly focus on influencing the pathological changes and do not normally alter positional changes of the disc for treatment of joint dysfunction, and determined that the disc repositioning is unnecessary in treatment of the pain and dysfunction associated with TMJ internal derangement.

The most common intra-articular injections following arthrocentesis are steroids, sodium hyaluronate, and nonsteroidal anti-inflammatory drugs (15-21).

The dextrose Prolotherapy is identified as a regenerative injection therapy, but is differentiated from other regenerative injection therapies, such as platelet-rich plasma and stem cell injection, by the absence of a biological agent (22).

This study was designed to verify the efficacy of arthrocentesis used normal saline followed by injection of the dextrose $50 \%$, in a single injection protocol, for management of the patients with TMJ internal derangement. The diagnosis of TMJ internal derangement was based on the clinical data and MRI findings.

The level of maximum pain at the function was the primary outcome variable. The subjective jaw function as jaw range of motion in millimeters, treatment tolerability, and perceived treatment effectiveness were the secondary outcomes. 


\section{MATERIALS AND METHODS}

The ethical clearance was obtained by the ethics committee before the study began and the selected patients were informed about the nature of the study and they signed informed consents.

This study was conducted on fourteen patients selected from those attending the outpatient clinic of the Oral and maxillofacial Surgery Department, Faculty of Dentistry, Alexandria University between July 2017 and February 2018.

The clinical prognosis of the conditions was evaluated according to following parameters: pain intensity, maximal mouth opening, lateral and protrusive movements, joint clicking, and regional tenderness.

All the patients have been followed at the end of after 24 hours, 1st, 2nd, 3rd, 4th, 5th, and 6th weeks.

\section{Inclusion criteria of patient selection}

- The patients selected for the present study were complaining from the clinical signs and symptoms of TMJ internal derangement and diagnosed on bases of clinical data and MRI findings. The patients had proved refractory to conservative treatment, were appropriate non-surgical modalities exhausted before placing the patients in a surgical category; These modalities included NSAID's, soft diet, moist heat, habit modification, and the patients wore an occlusal splint at least four weeks before the procedures

- The patients still suffered TMJ pain with one of the following criteria:

- Joint noises.

- Limited mouth opening (less than $35 \mathrm{~mm}$ ).

- Impeded lateral movement.

- Deviation toward the affected side of the opening and protrusion movements.

\section{Exclusion criteria}

- Previous TMJ surgical intervention.

- Patients with previous joint fractures.

- TMJ ankyloses.

- Current chemotherapy or radiotherapy.

- Compromising conditions as osteoporosis, organ transplantation or systemic immunological destruction disease as osteoarthritis.

- Patients receiving anticoagulation treatment or aspirin within 48 hours, corticosteroid injection and uncontrolled diabetes millets.

- TMJ infection.

The selected patients were divided equally into two groups:

- Group- A: Contained seven patients who treated by arthrocentesis used normal saline followed by injection of $2 \mathrm{ml}$ of $50 \%$ dextrose solution into the superior compartment of TMJ.

- Group- B: Contained seven patients who treated by arthrocentesis with normal saline alone.

Materials:

- Dextrose monohydrate solution 50.0G (50\%), osmolarity 2523 mOsm/L (Egypt Otsuka Pharmaceutical Co., S. A. E. 10th the of Ramadan City A. R. E.).

- Normal saline, $0.9 \%$ of sodium chloride intravenous infusion (Egypt Otsuka Pharmaceutical Co., S. A. E. 10th the of Ramadan City A. R. E.).

\section{Methods:}

I. Preoperative phase

1. Clinical diagnosis

a) Patient questionnaire: all details were recorded in a questionnaire by the examiner, including Personal data, Chief complaint, and Past history.

b)Clinical examination: general body examination, evaluation of the mandibular range of motion.

2. Occlusal splint therapy fabrication and insertion: occlusal splint was constructed and adjusted for each patient of TMD in both groups before treatment.

3. Radiological diagnosis of TMD, based on clinical diagnostic criteria was included in the study, the MRI was done for every patient in both groups; The position of the disc, disc configuration, osseous abnormalities of the condyle and temporal eminence, and effusion were recorded.

\section{Operative phase}

In both studied groups, the arthrocentesis used normal saline was done as following: (18-20). The surgical field was draped and painted with Betadine (contains povidoneiodine USP 7.5\% W/V. Manufactured by The Nile Co. for Pharmaceuticals and Chemical Industries Cairo - A.R.E. licensed by Mundidone-Basel-Switzerland).

The external auditory canal was protected from accumulation of blood and fluid. A local anesthetic for the block of the auriculotemporal nerve and infiltration into the areas of joint penetration using Mepecaine-L (each $1.8 \mathrm{ml}$ cartridge contains: Mepivacaine $\mathrm{HCl} 36 \mathrm{mg} / 1.8 \mathrm{ml}$ and Levonordefrin $\mathrm{HCl} 0.108 \mathrm{mg} / 1.8 \mathrm{ml}$; Produced by Alexandria Co. for pharmaceuticals, Alexandria, Egypt).

A line was drawn from the corner of the eye to the midpoint of the tragus (canthal-tragus line). The first entry puncture point first mark was made $10 \mathrm{~mm}$ from the tragus, and the second mark was made $2 \mathrm{~mm}$ below. A 20-gauge needle was then introduced at the first point and $2 \mathrm{ml}$ of saline was injected through this needle to distend the joint space using an inferolateral approach this needle will act as an inlet for solution indraft. Another 20-gauge needle was then inserted at the second point to establish a free flow of the solution through the joint space; Both needles were inserted into a depth of about $1.5 \mathrm{~cm}$. A syringe filled with saline was injected under pressure into the superior joint space through the first needle and the second needle provided the outflow for the saline. (Figure: 1)

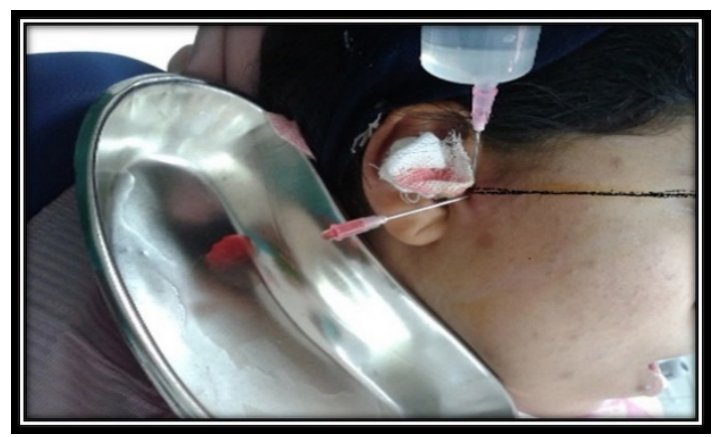

Figure (1): Arthrocentesis; Inlet and outlet needles insertion.

A total amount of $50 \mathrm{ml}$ of normal saline solution was used to lavage the superior joint space over the 15- to 20minute period and the outlet solution collected in a kidney dish. (Figure: 2) 


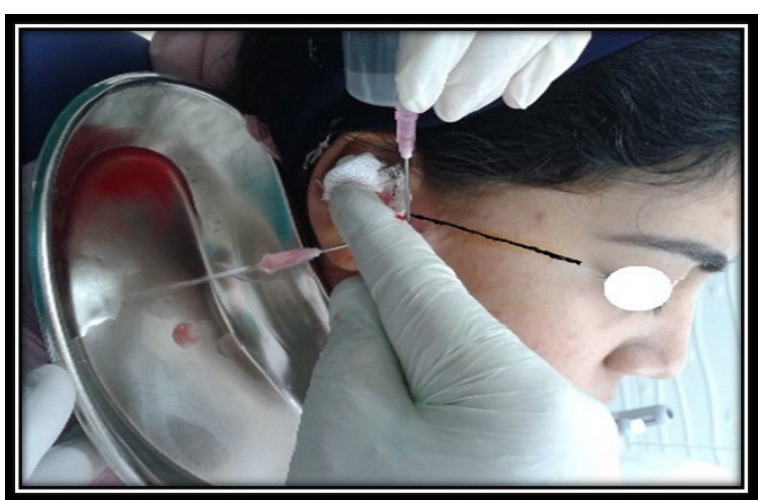

Figure (2): Arthrocentesis; disk lavage with normal saline.

For group-A patients, slow injection of $2 \mathrm{ml}$ of $50 \%$ dextrose through the first needle. (Figure: 3 )

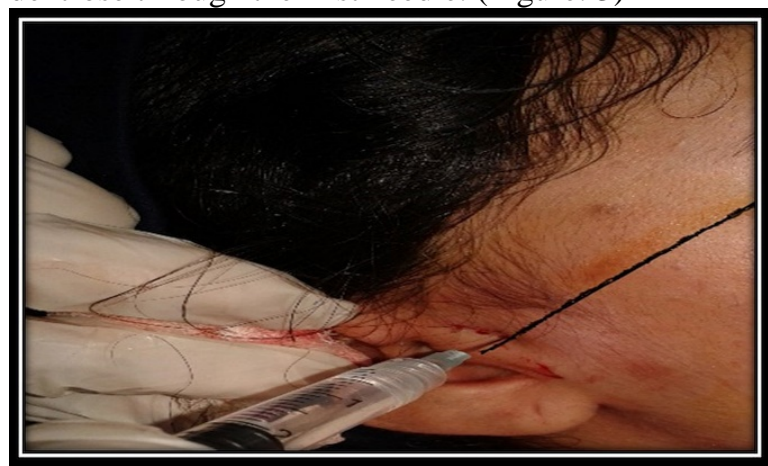

Figure (3): Dextrose prolotherapy; Injection of 50\% dextrose in superior joint space.

\section{Postoperative phase}

Postoperative car: After the procedures, all the patients were:

- Given postoperative instructions and advised to follow the soft diet and home physiotherapy such as the application of moist heat and range of motion exercises every 6 hours daily (23).

- Prescribed postoperative medication included an antibiotic $250 \mathrm{mg}$ Amoxicillin and $250 \mathrm{mg}$ Flucloxacillin (Flumox $500 \mathrm{mg}$, each capsule contains $250 \mathrm{mg}$ Amoxicillin and 250 mg Flucloxacillin, produced by: Egyptian Int. Pharmaceutical Industries Co. E.I.P.I.CO. Egypt), to be taken every 8 hours/day for 1week, and paracetamol $665 \mathrm{mg}$ (Panadol joint, each tablet contains paracetamol $665 \mathrm{mg}$. Produced by GlaxoSmithKline. UK) to be taken every 8 hours/day for 7 days.

Follow-up phase

The postoperative clinical evaluation included the following parameters:

- Pain level, using the Visual Analogue Scale (VAS).

- Maximum interincisal opening (MIO), Unassistant wide mouth opening.

- Active range of motion, functional movement as lateral and protrusive jaw movement.

- Joint clicking, the presence of joint noise on opening and closing.

- Tenderness of joint, tenderness over the TMJ area.

A. Early clinical evaluation

The clinical follow-up was done at the end of the 24 hours and 7 days postoperatively.

B. Late clinical evaluation

The clinical follow-up was done at the end of the 2nd, 3rd, 4th, 5th, 6th weeks postoperatively.
The statistical analysis of qualitative data was described using range (minimum and maximum), mean, standard deviation and median. Comparison between different studied groups regarding categorical variables was tested using the Chi-square test and Fisher's Exact test, While, McNemar test was used to analyze the significance between the different stages of time.

The distributions of quantitative variables were tested for normality using a Kolmogorov Smirnov test, the Shapiro Wilk test, and D'Agostino test, the parametric tests were applied to the normal data distribution. Comparison between two independent populations using an independent t-test and a paired t-test was used to analyze two paired data.

For abnormally distributed data, the comparison between two independent populations using the Mann Whitney test, to compare between the different periods the Wilcoxon signed rank test was applied.

\section{RESULTS}

The selected patients from both genders had a duration of presenting symptoms between 6- 42 months. Regarding the gender, $85.7 \%$ of the patients were females and the males represented $14.3 \%$ of total patients. Patients' ages ranged from 18 to 50 years, with a mean age of 29.07 a year, where $78.57 \%$ of total the patients less than 35 years old $81.81 \%$ of them were female patients.

All the patients diagnosed as TMD of different stages based on the clinical data and MRI findings. $78.57 \%$ of total cases reveals bilateral anterior disc displacement with reduction with respect to female cases only $18.18 \%$ were males. The female patients with bilateral anterior disc displacement with reduction represented $57.14 \%$ of groupA cases and $71.42 \%$ of group-B patients.

The repeated measurements collected and the changes over the 6-weeks follow-up were assessed in prospective longitudinal study in which every case was monitored at intervals after 24 hours, 1st, 2nd, 3rd, 4th, 5th, 6th weeks to evaluate pain intensity, maximal interincisal opening, lateral protrusive movements, joint clicking, and regional tenderness.

\section{Pain intensity}

The pain intensity scale decreased along the different postoperative periods in both studied groups. The average of a reduction in the scale of the pain intensity of group-A was $93.38 \%$, and of group-B was $91.23 \%$.

The statistical analysis of the difference among the same group over the 6 -weeks has been significant in both studied groups, except for the period at the end of 24 hours that was insignificant.

In comparing postoperative pain intensity of both studied groups, the statistical analysis revealed an insignificant difference. Clinically, the pain intensity in group-A patients disappeared at end of the 3rd week, while in group-B patients, the pain disappeared at the end of 4 th week. (Table: 1 )

The statistical analysis of pain- MIO relationship of group-A, the difference was significant at the end of the 24 hours and the 1st week follow-up.

The statistical analysis of pain intensity- lateral movement relationship of group-A, the right-side difference was insignificant throughout the whole postoperative periods, while the left-side was significant at the end of the 1st and 2nd weeks follow-up. 
Table (1): Relation between pain intensity and different functional jaw movements in group-A.

\begin{tabular}{|c|c|c|c|c|c|c|c|c|c|}
\hline & & \multicolumn{8}{|c|}{ Pain intensity score } \\
\hline & & \multirow{2}{*}{ ڤั } & \multicolumn{2}{|c|}{ Early follow up } & \multicolumn{5}{|c|}{ Late follow up } \\
\hline & & & $\begin{array}{l}\text { After } \\
24 \text { hour }\end{array}$ & $\begin{array}{c}\text { After } \\
1 \text { st } \\
\text { week }\end{array}$ & $\begin{array}{c}\text { After } \\
\text { 2nd } \\
\text { week }\end{array}$ & $\begin{array}{c}\text { After } \\
\text { 3rd } \\
\text { week }\end{array}$ & $\begin{array}{c}\text { After } \\
4 \text { th } \\
\text { week }\end{array}$ & $\begin{array}{c}\text { After } \\
5 \text { th } \\
\text { week }\end{array}$ & $\begin{array}{c}\text { After } \\
6 \text { th } \\
\text { week }\end{array}$ \\
\hline \multirow{2}{*}{\begin{tabular}{|l} 
Maximal \\
interincisal \\
opening
\end{tabular}} & $r_{\mathrm{s}}$ & $-0.810^{*}$ & $-0.899^{*}$ & $-0.798^{\circ}$ & -0.546 & -0.642 & - & - & - \\
\hline & $\mathrm{p}$ & $0.027^{*}$ & $0.006^{*}$ & $0.032^{*}$ & 0.205 & 0.120 & - & - & - \\
\hline \multirow{2}{*}{\begin{tabular}{|l} 
Right \\
Lateral Jaw \\
Movement
\end{tabular}} & $\mathbf{r}_{\mathrm{s}}$ & -0.468 & -0.242 & -0.091 & -0.468 & -0.342 & - & - & - \\
\hline & p & 0.290 & 0.602 & 0.846 & 0.290 & 0.453 & - & - & - \\
\hline \multirow{2}{*}{$\begin{array}{l}\text { Left Lateral } \\
\text { Jaw } \\
\text { Movement }\end{array}$} & $\mathrm{rs}_{\mathrm{s}}$ & $-0.816^{*}$ & -0.593 & $-0.837^{*}$ & $-0.970^{*}$ & -0.525 & - & - & - \\
\hline & $\mathbf{p}$ & $0.025^{*}$ & 0.160 & $0.019^{*}$ & $<0.001^{*}$ & 0.227 & - & - & - \\
\hline \multirow{2}{*}{$\begin{array}{l}\text { Protrusive } \\
\text { jaw } \\
\text { movement }\end{array}$} & $r_{\mathrm{s}}$ & -0.722 & -0.730 & $-0.837^{\circ}$ & $-0.970^{\circ}$ & -0.642 & - & - & - \\
\hline & $\mathbf{p}$ & 0.067 & 0.062 & $0.019^{*}$ & $<0.001^{*}$ & 0.120 & - & - & - \\
\hline
\end{tabular}

*: Statistically significant at $\mathrm{p} \leq 0.05$

rs: Spearman coefficient

The statistical analysis of pain intensity- protrusive movement relationship of group-A, the difference was significant at the end of the 1st, and 2nd weeks follow-up.

\section{Maximum interincisal opening (MIO)}

Preoperatively, a limited mouth opening was obvious. There was an increased MIO along the whole postoperative periods, the average of an increased MIO of group-A was 83.40\% and of group-B was $64.02 \%$.

The statistical analysis of preoperative- postoperative MOI within the same studied group, the differences found to be a significant along the whole postoperative follow-up periods in the both studied groups.

In comparing MIO of the both studied groups, the statistical difference was a significant at the end of the 3rd ,4th, 5th, and 6th weeks follow-up periods. (Table: 2)

Table (2): Comparison between the two studied groups according to maximum interincisal opening (MIO)

\begin{tabular}{|c|c|c|c|c|}
\hline $\begin{array}{c}\text { Maximum } \\
\text { interincisal } \\
\text { opening }\end{array}$ & Group-A & Group-B & $\mathbf{t}$ & $\mathbf{p}$ \\
\hline $\begin{array}{l}\text { Pre-operative } \\
\text { Min. - Max. } \\
\text { Mean } \pm \text { SD. } \\
\text { Median }\end{array}$ & $\begin{array}{l}19.0-29.0 \\
23.14 \pm 3.53 \\
23.0\end{array}$ & $\begin{array}{l}22.0-30.0 \\
24.43 \pm 2.82 \\
24.0\end{array}$ & 0.753 & 0.466 \\
\hline $\begin{array}{l}\text { After } 24 \text { hour } \\
\text { Min. - Max. } \\
\text { Mean } \pm \text { SD. } \\
\text { Median }\end{array}$ & $\begin{array}{l}32.0-37.0 \\
34.43 \pm 1.62 \\
35.0\end{array}$ & $\begin{array}{l}32.0-39.0 \\
34.14 \pm 2.54 \\
33.0\end{array}$ & 0.251 & 0.806 \\
\hline $\begin{array}{l}\text { After 1st week } \\
\text { Min. - Max. } \\
\text { Mean } \pm \text { SD. } \\
\text { Median }\end{array}$ & $\begin{array}{l}37.0-43.0 \\
40.29 \pm 1.98 \\
40.0\end{array}$ & $\begin{array}{l}36.0-43.0 \\
39.57 \pm 2.57 \\
39.0\end{array}$ & 0.583 & 0.571 \\
\hline $\begin{array}{l}\text { After 2nd } \\
\text { week } \\
\text { Min. - Max. } \\
\text { Mean } \pm \text { SD. } \\
\text { Median }\end{array}$ & $\begin{array}{l}39.0-45.0 \\
41.86 \pm 2.67 \\
40.0\end{array}$ & $\begin{array}{l}36.0-43.0 \\
39.43 \pm 2.70 \\
40.0\end{array}$ & 1.692 & 0.117 \\
\hline $\begin{array}{l}\text { After 3th week } \\
\text { Min. - Max. } \\
\text { Mean } \pm \text { SD. } \\
\text { Median }\end{array}$ & $\begin{array}{l}43.0-47.0 \\
44.71 \pm 1.25 \\
45.0\end{array}$ & $\begin{array}{l}36.0-45.0 \\
41.0 \pm 3.61 \\
43.0\end{array}$ & 2.574 & $\begin{array}{l}0.035 \\
*\end{array}$ \\
\hline $\begin{array}{l}\text { After 4th week } \\
\text { Min. - Max. } \\
\text { Mean } \pm \text { SD. } \\
\text { Median }\end{array}$ & $\begin{array}{l}43.0-47.0 \\
45.29 \pm 1.25 \\
45.0\end{array}$ & $\begin{array}{l}37.0-45.0 \\
41.43 \pm 3.26 \\
43.0\end{array}$ & 2.923 & 0.020 \\
\hline $\begin{array}{l}\text { After 5th week } \\
\text { Min. - Max. } \\
\text { Mean } \pm \text { SD. } \\
\text { Median }\end{array}$ & $\begin{array}{l}43.0-47.0 \\
45.29 \pm 1.25 \\
45.0\end{array}$ & $\begin{array}{l}37.0-45.0 \\
41.57 \pm 3.05 \\
43.0\end{array}$ & 2.982 & $\mathbf{0 . 0 1 8}$ \\
\hline $\begin{array}{l}\text { After 6th week } \\
\text { Min. - Max. } \\
\text { Mean } \pm \text { SD. } \\
\text { Median }\end{array}$ & $\begin{array}{l}43.0-47.0 \\
45.29 \pm 1.25 \\
45.0\end{array}$ & $\begin{array}{l}37.0-45.0 \\
41.57 \pm 3.05 \\
43.0\end{array}$ & 2.982 & 0.018 \\
\hline
\end{tabular}

There was direct positive relationship of MIO with lateral and protrusive movements; The statistical analysis of MIO-lateral movements relationship, the difference found to be significant at the end of the 24 hours, the 5th and 6th weeks follow-up.

The statistical analysis of MIO- protrusive movements relationship of group-A, the different was significant at the end of the 24 hours, the1st, 5th, and 6th weeks follow-up.

\section{Lateral movement}

The lateral movement in the right and the left side where measured in both studied groups. There was increased in the lateral movement during postoperative follow-up periods in both studied groups.

The statistical analysis of preoperative and postoperative periods within the same group, the differences found to be a significant in both studied groups along the whole postoperative follow-up periods.

In comparing the difference between both studied groups, the right-side revealed a significant difference at the end of 24 hours, 1st, 4th, 5th, and the 6th weeks; While the left-side lateral movement found to be an insignificant along the whole postoperative periods.

The statistical analysis of lateral excursion- protrusive movement association of group- $A$, the right-side revealed significant difference at the end of the 4th, 5th, and the 6th weeks, while the left-side found to be significant throughout the whole period, except at the end of the 24 hours.

\section{Protrusive movement}

The protrusive movement increased throughout the whole postoperative periods. The postoperative average of an increased protrusive movement of group-A was $95.24 \%$, and of group-B was $73.83 \%$.

The statistical analysis preoperative and postoperative follow-up within the same studied group, the difference found to be significant throughout the whole studied periods in the both studied groups.

In comparing postoperative protrusive movement of both studied groups, the statistical difference was significant at the end of the 1 st week were $p=0.041$, supervened by intervals of insignificant at the end of the 2nd and the 3rd weeks, eventually the statistical difference has been significant at the end of the 4th, 5th and the 6th weeks follow-up were $\mathrm{p}=0.014,0.003$, and 0.003 respectively.

\section{TMJ clicking}

In group-A, $100 \%$ had detectable joint sounds preoperatively. At the end of the 24 hours, there was $42.9 \%$ of the patients had detectable joint sound; Along the interval between 1st week and the end of the 6th weeks, $14.3 \%$ of the patients had detectable joint sound.

The statistical analysis of preoperative- postoperative of group-A, the difference was significant along the whole period of the follow-up except at the end of the 24 hours.

In group- $B, 85.7 \%$ of the patients had detectable joint sound preoperatively. At the end of the 24 hours, $71.4 \%$ of the patients had detectable joint sound. Along the intervals between the end of the 1st week and the end of the 6th, the average did not change where $42.9 \%$ of the patients had detectable joint clicking.

The statistical analysis of preoperative- postoperative TMJ-clicking of group-B, the difference found to be insignificant throughout the whole periods of the follow-up.

In comparing the postoperative joint clicking of both studied groups, the statistical difference throughout the whole follow-up periods was insignificant. (Table: 3) 
Table (3): Comparison between two studied groups according to Joint clicking (JC)

\begin{tabular}{|c|c|c|c|c|c|c|c|c|c|c|}
\hline & \multirow{2}{*}{\multicolumn{2}{|c|}{$\begin{array}{l}\text { Pre- } \\
\text { operative }\end{array}$}} & \multicolumn{8}{|c|}{ Postoperative Joint clicking } \\
\hline & & & \multicolumn{2}{|c|}{$\begin{array}{c}\text { After } 24 \\
\text { hour }\end{array}$} & \multicolumn{2}{|c|}{$\begin{array}{l}\text { After 1st } \\
\text { week }\end{array}$} & \multicolumn{2}{|c|}{$\begin{array}{l}\text { After 2nd } \\
\text { week }\end{array}$} & \multicolumn{2}{|c|}{$\begin{array}{l}\text { After 6th } \\
\text { week }\end{array}$} \\
\hline & $n$ & $\%$ & $n$ & $\%$ & $n$ & $\%$ & $n$ & $\%$ & $n$ & $\%$ \\
\hline \multicolumn{11}{|l|}{ Group- A } \\
\hline $\begin{array}{l}\text { Clicking } \\
\text { joint }\end{array}$ & 7 & $\begin{array}{c}100 . \\
0\end{array}$ & 3 & $\begin{array}{c}42 . \\
9\end{array}$ & 1 & 14.3 & 1 & 14.3 & 1 & 14.3 \\
\hline $\begin{array}{l}\text { Non clicking } \\
\text { joint }\end{array}$ & 0 & 00.0 & 4 & $\begin{array}{c}57 . \\
1\end{array}$ & 6 & 85.7 & 6 & 85.7 & 6 & 85.7 \\
\hline${ }^{\mathrm{FE}} \mathbf{p}_{\mathbf{1}}$ & & & \multicolumn{2}{|c|}{0.070} & \multicolumn{2}{|c|}{$0.005^{*}$} & \multicolumn{2}{|c|}{$0.005^{*}$} & \multicolumn{2}{|c|}{$0.005^{*}$} \\
\hline \multicolumn{11}{|l|}{ Group- B } \\
\hline $\begin{array}{l}\text { Clicking } \\
\text { joint }\end{array}$ & 6 & 85.7 & 5 & $\begin{array}{c}71 . \\
4 \\
\end{array}$ & 3 & 42.9 & 3 & 42.9 & 3 & 42.9 \\
\hline $\begin{array}{l}\text { Non clicking } \\
\text { joint }\end{array}$ & 1 & 14.3 & 2 & $\begin{array}{c}28 . \\
6 \\
\end{array}$ & 4 & 57.1 & 4 & 57.1 & 4 & 57.1 \\
\hline${ }^{\mathrm{FE}} \mathbf{p}_{\mathbf{1}}$ & & & \multicolumn{2}{|c|}{1.000} & \multicolumn{2}{|c|}{0.266} & \multicolumn{2}{|c|}{0.266} & \multicolumn{2}{|c|}{0.266} \\
\hline${ }^{\mathrm{FE}} \mathbf{p}_{2}$ & \multicolumn{2}{|c|}{1.000} & \multicolumn{2}{|c|}{0.592} & \multicolumn{2}{|c|}{0.559} & \multicolumn{2}{|c|}{0.559} & \multicolumn{2}{|c|}{0.559} \\
\hline
\end{tabular}

p2: p for comparing between the two groups

\section{Regional tenderness}

All the patients in both studied groups had regional tenderness preoperatively.

In group-A, at the end of 24 hours, there was $42.8 \%$ of the patients had joint tenderness; Along the period of follow-up between the end of the 1st week and the end of the 6 th week, there was $14.3 \%$ of the total patients had regional tenderness.

The statistical analysis of regional tenderness of groupA, the difference was significant along the whole periods of the follow-up except the period of 24 hours.

In group- $B$, at the end of the 24 hours, there was $71.4 \%$ of the patients had joint tenderness; Along the period of follow-up between the end of the 1st week and the end of the 6 th week, there was $42.9 \%$ of the patients had joint tenderness.

In comparing regional tenderness of the both studied groups, the statistical difference was insignificant along the whole postoperative follow-up.

\section{Postoperative complications}

Postoperative complication was recorded in this study; Three female patients in group-B have been reported mild preauricular swelling in immediate postoperative phase. One female patient in group-B reported difficult closure of the eyelid.

\section{DISCUSSION}

The patients selected for the present study were complaining from the clinical signs and symptoms of TMJ internal derangement. Although the clinical examination is useful in diagnosing patients with TMD, however, the diagnostic accuracy is questionable. Therefore, the clinical diagnosis was confirmed by MRI findings. This procedure agreed with Kumar et al (24) and katzberg et al (25), who suggested an MRI for all patients suffered TMJ dysfunction.

In this study, dextrose solution has been used as a regenerative injection Prolotherapy. Dextrose Prolotherapy is differentiated from other regenerative injection therapies, such as platelet-rich plasma (PRP) and stem cell injection, by the absence of a biological agent. According to Reeves et al (22), the use of dextrose Prolotherapy reported being safe and used for myofascial pain syndrome come from level-2 evidence. Moreover, Shaffer et al (26), suggested that dextrose alone or as mixed with sterile water or with lidocaine can be used effectively intradiscal, peridiscal, or for management of chronic muscular spasm either in muscle tender trigger points or in a terminal attachment of the muscle.

In this present study, hypertonic and high concentration dextrose solution was used with a significant result in a reduction of the pain intensity, and MIO. This results concordant with results published by Rabago et al (27), who found hypertonic dextrose was the most commonly used Prolotherapy solution, with favorable outcomes shown in multiple clinical trials.

In this study, single injection technique was used for management of patients suffered TMD. Although Refai et al (28), and Hakala and Ledermann (29), who suggested a series of 3-5 injections to obtain a confirmed therapeutic effect. Finding in this study found that the patients had a satisfactory outcome were the reduction in pain intensity was $93 \%$ and the improvement in MIO was $83.4 \%$, these results comparable to criteria of success described by Kaneyama et al (30), and a review article which included nineteen studies done by Al-Belasy and Dolwick (31), who reported the success rate at $83.2 \%$. Moreover, single injection dextrose being safer were the frequency of visits to hospital reduced, side effects diminished, and easily accepted by the patients.

The results of the present study showed a significant reduction in pain intensity in both studied groups. This finding agreed with the results obtained by Nitzan (4), who reported a significant decrease of pain intensity after arthrocentesis.

Russell et al (32), and Stecker and Stevenson (33) who reported that there was sensorineural analgesic mechanism of direct injection of dextrose into the intra-articular and extra-articular tissues. The finding in this study found no statistically significant difference in pain intensity between both studied groups postoperatively. However, the average pain reduction was greater in group-A by $2.15 \%$, and the pain has been disappeared more rapidly in group-A.

TMJ's with internal derangement share common interrelated symptoms such as pain, limitation in maximal mouth opening, and impeded jaw movement. The finding in this study found that there was a negative relationship between the pain intensity and functional jaw movements, where a decreased pain intensity accompanied by the improvement of MIO, lateral, and protrusive jaw movement. The finding of a causal relationship in this study comes in agreement with Carvajal and Laskin (34), who reported that the decreased pain intensity caused increased maximal mouth opening, which in turn causes decreased TMJ dysfunction. Thus, correction of one problem can lead to correction of the other two factors.

The results of this study, showed postoperative significant difference in $\mathrm{MIO}$, lateral and protrusive movement between group-A and group- $\mathrm{B}$. This finding supported by several clinical studies $(17,18,21)$, suggested that the arthrocentesis produces improvement in all clinical outcomes in a selected group of patients, especially when supplemented by intra-articular injection. Recent studies in basic science done by Reeves et al (22), and Vankdoth et al 
(35), who reported that the dextrose applied via the intraarticular route causing a stimulation of the chondrogenic effect of intra-articular tissue; Hauser et al (36), suggested that the dextrose has independent effects that may promote local healing of chronically injured extraarticular and intra-articular tissue through stimulating different pathways.

In this study, preoperative detectable joint sound in group-A was $100 \%$ and $85.7 \%$ of group-B. There was a distinct reduction in detectable joint sound during the postoperative periods. The statistical analysis of difference between preoperative and postoperative periods of group-A found to be significant, in contrast to insignificant difference of group-B along the whole periods of follow-up.

In comparing postoperative joint clicking of both studied groups, the difference found to be statistically insignificant. However, the average of reduction of detectable joint sound was greater in group-A, in which the difference between both studied groups at the end of the 6th week follow-up was $28 \%$. This finding was in agreement with the results obtained by several authors $(35,22,37)$ who denotes that dextrose is not possess their actions as a lubricant only but also induces repair of articular surfaces. Moreover, Mobasheri (37), suggested that the increased local dextrose cause release of the transforming growth factor- $\beta$ (TGF- $\beta$ ), which in turn accelerate and promote a mechanism of repair. Hauser et al (38), and kim et al (39), found that the increase of extra-cellular dextrose concentration from prolotherapy injections causes cells to proliferate and an increase in cell protein synthesis, DNA synthesis, cell volume, and proliferation.

In this study, preoperatively all the patients had regional tenderness in both studied groups; In early postoperative follow-up, there was remarkable progress in patients had been cured; At the end of the 6th week, the patients had been suffered regional tenderness were $14.3 \%$ of group-A, and $42.9 \%$ of group-B.

In comparing of both studied group, the difference in joint tenderness found to be insignificant throughout the whole periods of the follow-up. These findings supported by several authors $(3,4,5,12)$, mentioned that the washingout of the inflammatory mediators and cytokines by TMJ lavage has clinical benefit such as a reduction of the pain and TMJ tenderness. Hauser et al (40) reported that the dextrose injection attracts granulocytes and macrophages which accelerate inflammatory cascade and healing processes. These finding concordant with the results in this study were the percentage of the patients had been cured at the end of the 6th week follow-up in group- A greater than in group-B by $28.5 \%$.

In this study, some postoperative complication was recorded, three patients have been reported mild preauricular swelling in the immediate postoperative phase, due to extravasation of fluid into surrounding tissues, which resolved by the second post-operative day. One patient reported difficult closure of the eyelids due to transient facial nerve anesthesia and resolved after two hours postoperatively. Despite the rarity of such events, the complications directly relate to the training of the operator.

Finally; the findings of the present study support the concept that the performance of arthrocentesis produces improvement in all clinical outcomes in a selected group of patients, especially when supplemented by intra-articular injection.

\section{CONCLUSION}

According to the results of the present study, we conclude that the management of TMD by Dextrose Prolotherapy with single-injection protocol offered effective clinical benefit, regarding the reduction of pain and TMJ dysfunction, with a less invasive procedure and minimal morbidity.

\section{CONFLICT OF INTEREST}

The authors declare that they have no conflicts of interest.

\section{REFERENCES}

1. Juniper RP. The pathogenesis and investigation of TMJ dysfunction. Brit J Oral Maxillofac Surg. 1987; 25:105-12.

2. Stegenga B, de Bont LG, Boering G, van Willigen JD. Tissue responses to degenerative changes in the temporomandibular joint: A review. J Oral Maxillofac Surg. 1991; 49:1079-88.

3. Milam SB. Molecular biology of temporomandibular joint disorders: proposed mechanisms of disease. J Oral Maxillofac Surg. 1995; 53:1448-54.

4. Nitzan DW. The process of lubrication impairment and its involvement in temporomandibular joint disc displacement: a theoretical concept. J Oral Maxillofac Surg. 2001; 59:36-45.

5. Nitzan DW. Adhesive force: the underlying cause of the disc anchorage to the fossa and/or eminence in the temporomandibular joint-a new concept. Int $\mathrm{J}$ Oral Maxillofac Surg. 2002; 31:94-9.

6. Wilkes $\mathrm{CH}$. Internal derangements of the temporomandibular joint: pathological variation. Arch Otolaryngol Head Neck Surg. 1989; 115:469-77.

7. Dolwick MF, Kaytzberg RW, Helms CA. Internal derangement of the temporomandibular joint. Fact or fiction. J Prosthet Dent. 1983; 49:415-8.

8. Farrar WB. Characteristics of the condylar path in internal derangement of the TMJ. J Prosthet Dent. 1978; 39:31923.

9. Nitzan D, Dolwick M, Martinez G. Temporomandibular Joint Arthrocentesis: A Simplified Treatment for Severe Limited Mouth opening. J Oral Maxillofac Surg. 1991; 11:1163-7.

10. Yura S, Totsuka Y. The relationship between the effectiveness of arthrocentesis under sufficient pressure and conditions of the temporomandibular joint. J Oral Maxillofac Surg. 2005; 63:225-8.

11. Yura S, Yoshikawa T, Inoue N. Can arthrocentesis release intracapsular adhesions; Arthroscopic findings before and after irrigation under sufficient hydraulic pressure. J Oral Maxillofac Surg. 2003; 61:1253-6.

12. Stegenga B. Nomenclature and classification of temporomandibular joint disorders. J Oral Rehabi 2010; 37:760-765.

13. Sato J, Segami N, Nishimura M, Demura N, Yoshimura H, Yoshitake Y, et al. Expression of interleukin-6 in synovial tissues in patients with internal derangement of the temporomandibular joint. Br J Oral Maxillofac Surg. 2003; 41:95-101.

14. Sato J, Segami N, Nishimura M, Kaneyama K, Demura $\mathrm{N}$, Yoshimura $\mathrm{H}$. Relation between the expression of vascular endothelial growth factor in synovial tissues and 
the extent of joint effusion seen on magnetic resonance imaging in patients with internal derangement of the temporomandibular joint. Br J Oral Maxillofac Surg. 2003; 41:88-94.

15. Kaneyama K, Segami N, Nishimura M, Sato J, Fujimura $\mathrm{K}$, Yoshimura H.The Ideal lavage volume of Bradykinin, Interleukin-6 and protein from the temporo- mandibular joint by arthrocentesis. J Oral Maxillofac Sug. 2004; 62:657-61.

16. Al-Belasy FA, Dolwick MF. Arthrocentesis for the treatment of temporomandibular joint closed lock: A review article. Int J Oral Maxillofac Surg. 2007; 36:77382.

17. Said S. Comparison of arthrocentesis with and without injection of sodium hyaluronate in the management of temporomandibular joint disorders. Master Thesis. Alexandria University, 2010.

18. Lotfy S. Comparative study between low and high molecular weight hyaluronic acid injections after arthrocentesis in the treatment of temporomandibular joint disorders. Master Thesis. Alexandria University 2014.

19. EL-said S. comparative study of arthrocentesis with or without using piroxicam in the management of temporomandibular joint disorders. Master Thesis. Alexandria University, 2015.

20. Ethunandan M, Wilson AW. Temporomandibular joint arthrocentesis- more questions than answers. J Oral Maxillofac Surg. 2006; 64:952-5.

21. Nabil L. Clinical Assessment of Arthrocentesis using ozonized water with sodium hyaluronate injection in the management of TMJ Disorders. Master Thesis. Alexandria University; 2008.

22. Reeves K, Rabago D. Dextrose prolotherapy, A narrative review of basic science, clinical research, and best treatment recommendations. Phys Med Rehabil Clin N Am. 2016; 27:783-823.

23. Arati S. Neeli M, Kotrashetti S, Baliga S. Arthrocentesis for the Treatment of Internal Derangement of the Temporomandibular Joint. J Maxillofac Oral Surg. 2010; 9:350-4.

24. Kumar R, Pallagatti S, Sheikh S, Mittal A, Gupta D, Gupta S. Correlation Between Clinical Findings of Temporomandibular Disorders and MRI Characteristics of Disc Displacement. The open Dentistry J, 2015, 9: 273-81

25. Katzberg RW, Westesson PL, Tallents RH, Drake CM. Orthodontics and temporo- mandibular joint internal derangement. Am J Orthod Dentofacial Orthop. 1996 May;109:515-20.

26. Shaffer SM, Brismée JM, Sizer PS, Courtney CA. Temporomandibular disorders Part 1: anatomy and examination/ diagnosis. J Man Manip Ther. 2014; 22:2-12.

27. Rabago D, Slattengren A, Zgierska A. Prolotherapy in primary care practice. Prim Care J. 2010; 37:65-80.

28. Refai H, Altahhan O, Elsharkawy R. The efficacy of dextrose prolotherapy for temporomandibular joint hypermobility: a preliminary prospective, randomized, double-blind, placebo-controlled clinical trial. J Oral Maxillofac Surg. 2011; 69:2962-70.

29. Hakala RV, Ledermann KM. The use of prolotherapy for temporomandibular joint dysfunction. J Prolother. 2010; 2:439-46.
30. Kaneyama K, Segami N, Nishimura M, Fujimura K, and Yoshimura $H$. The ideal,lavage volume for removing bradykinin, interlukin-6, and protein from the temporomandibular joint by arthrocentesis. J Oral Maxillofac Surg 2004; 62: 657-661.

31. Belasy FA, Dolwick MF. Arthrocentesis for the treatment of temporomandibular joint closed lock: a review article Int J Oral Maxillofac Surg 2007 Sep;36 (9):773-82.

32. Russell JW, Golovoy D, Vincent AM, Mahendru P, Olzmann JA, Mentzer A, et al. High glucose-induced oxidative stress and mitochondrial dysfunction in neurons. Fed Am Soci Experi Biol (FASEB) J. 2002; 16:1738-48.

33. Stecker MM, Stevenson M. Effect of glucose concentration on peripheral nerve and its response to anoxia. Muscle Nerve J. 2014; 49:370-7.

34. Carvajal W, Laskin DM. Long-term evaluation of arthrocentesis for the treatment of internal derangements of the temporomandibular joint. J Oral Maxillofac Surg 2000; 58: 852-55.

35. Vankdoth A, Talla H, vijayalaxmi N, Madhulatha G. Prolotherapy- A venturing Treatment for the Temporomandibular joint disorder. Inter Scientific Study J. 2014; 1:27-30.

36. Hauser RA, Hauser MA, Blakemore KA. Dextrose prolotherapy and pain of chronic TMJ dysfunction. Pract Pain Manag. 2007; 7:49-55.

37. Mobasheri A. Glucose: an energy currency and structural precursor in articular cartilage and bone with emerging roles as an extracellular signaling molecule and metabolic regulator. Front Endocrinol. 2012; 3:1-10.

38. Hauser RA, Lackner JB, Steilen-Matias D, Harris DK. A Systematic Review of Dextrose Prolotherapy for Chronic Musculoskeletal Pain. Clin Med Insights Arthritis Musculoskelet Disord 2016 Jul; 7:139-59.

39. Kim HJ, Jeong T, Kim WS, Park YS. Comparison of histological changes in accordance with the level of dextrose-concentration in experimental Prolotherapy model. J Korean Acad Rehab Med. 2003;27:935-40.

40. Hauser RA, Maddela HS, Alderman D, Baehnisch G, Banner R, Blakemore PJ, et al. The case for prolotherapy: Journal of Prolotherapy International Medical Editorial Board Consensus Statement on the Use of Prolotherapy for Musculoskeletal Pain. J Prolotherapy 2011 Dec;3:744-64. 